Fall 2008

\title{
Critical analysis of Chicana/o children's literature: Moving from cultural differences to sociopolitical realities
}

\author{
Rosemary Gonzalez \\ California State University Northridge \\ Theresa Montaño \\ California State University Northridge
}

Follow this and additional works at: https://digitalscholarship.unlv.edu/jpme

\author{
Repository Citation \\ Vol. 3: No. 1, Article 6. \\ DOI: 10.9741/2161-2978.1014 \\ Available at: https://digitalscholarship.unlv.edu/jpme/vol3/iss1/6
}

Gonzalez, Rosemary and Montaño, Theresa (2008) "Critical analysis of Chicana/o children's literature: Moving from cultural differences to sociopolitical realities," Journal of Praxis in Multicultural Education:

This Article is protected by copyright and/or related rights. It has been brought to you by Digital Scholarship@UNLV with permission from the rights-holder(s). You are free to use this Article in any way that is permitted by the copyright and related rights legislation that applies to your use. For other uses you need to obtain permission from the rights-holder(s) directly, unless additional rights are indicated by a Creative Commons license in the record and/ or on the work itself.

This Article has been accepted for inclusion in Journal of Praxis in Multicultural Education by an authorized administrator of Digital Scholarship@UNLV. For more information, please contact digitalscholarship@unlv.edu. 


\title{
Critical Analysis of Chicana/o Children's Literature: Moving from Cultural Differences to Sociopolitical Realities
}

\author{
Rosemary Gonzalez and Theresa Montaño
}

In an effort to humanize the curriculum, to honor student voice and identity, and tap the cultural and linguistic knowledge of our students, two teacher educators engage their preservice teachers in the collective use of Chicana/o children's literature. The authors describe a series of questions they designed in order to scaffold teachers' ability to analyze the extent to which literature stereotypes Chicano/a children, rejects their linguistic realities, and/or minimizes existing inequities. A series of assignments challenge preservice teachers' simplistic conceptualizations of inequality. In addition, they create a critical literacy poster/lesson plan, which can empower youth by simultaneously fostering academic competence and engaging them in social action.

In the Los Angeles Unified School District (LAUSD), over 60 percent of students are Latino, and almost 30 percent are English Learners (Education Data Partnership, 2007). However, the teaching of reading and writing is often compromised due to an "English only" mandate which forces teachers to teach primarily in English. The mandate stems from Proposition 227 (English for the Children) passed by California voters in 1996. The consequences of Proposition 227 have resulted in a reductionist approach to literacy instruction. For example, in an effort to increase student scores on standardized exams, LAUSD adopted the Open Court reading curriculum, which requires the implementation of scripted reading programs. In classrooms where English is the only means of instruction reading strategies are often restricted to the decoding of words and student reading is nothing more than deciphering simplistic texts (Gutierrez et. al., 2002; Montaño \& Lopez-Metcalfe, 2003; Ulanoff \& Vega-Castaneda, 1999). Moreover, when the primary language of instruction is English, students are unable to develop a strong foundation in their primary language, which can foster a successful transition to increased academic proficiency in English

Rosemary Gonzalez is an associate professor of Child and Adolescent Development and Chicana/o Studies at California State University Northridge. She conducts research on the academic resilience of Mexican Americans and has published work on engaging preservice teachers in critically analyzing stereotypes of the Chicana/o child. Theresa Montaño is an associate professor of Chicana/o Studies at Cal State Northridge. Theresa is also a member of the NEA Board of Directors, higher education and past president of the National Association for Multicultural Education. 
(August \& Shanahan, 2006; Baker, 2001; Collier \& Thomas, 1998; Cummins, 1981; Cummins, 1994).

If the primary purpose of reading instruction is to introduce students to academically rigorous information and engaging texts, students who cannot comprehend the reading material or connect with the meaning of the text cannot learn. The aforementioned policies hinder the efforts of future teachers to humanize the curriculum, honor student voice and tap the cultural and linguistic knowledge of students. In contrast, a culturally responsive curriculum has the potential to increase student's academic competence and engagement in the classroom (Tan, 2001).

\section{When Multicultural Literature is Counter-Productive}

Children's literature has become more ethnically diverse and readily available for teacher use in the classroom. In fact, the diversification of children's literature has led to the emergence of literary awards such as the Pura Belpre award, the National Association of Multicultural Education's book award, and the Coretta Scott King award. The inclusion of more cultural texts in the classroom is a noble effort to bridge "misunderstandings," expose children to other cultures, and build unity. However, much of the rhetoric about multicultural children's literature focuses on affirming the "ethnic" child and "celebrating" unique cultural traditions. This can be problematic for several reasons.

When multicultural literature is used to affirm "other" ethnic groups by including "interesting" nuances or cultural differences, it tends to essentialize an ethnic group and promote a tourist approach to literature. Taking an essentialist or tourist approach to multicultural children's literature may actually serve to counteract a teacher's intent to "bridge cultural understanding" and instead promotes oversimplifications and cultural stereotypes (Shedivy, 2007). Second, incorporating multicultural literature can be problematic if teachers simply add cultural stories to the curriculum with minimal or tangential academic goals in mind (Brookhart \& Freeman, 1992; Easter, Shultz, Neyhart, \& Reck, 1999). Third, the inclusion of multicultural literature can also be problematic if conversations about prejudice do not include a deeper understanding of privilege and institutional racism. In other words, if the roots of racism and inequality are not addressed a teacher's goal of building unity will fall short (Smith \& Heckman, 1995).

In sum, it has become especially important for teachers to critically analyze children's literature and the criteria they use when adopting literary materials for their classrooms. However, students who are new to the examination of "differences" are not likely to be adept at posing or responding 
to deeper analytical questions about structural inequality or issues of power and privilege. The mere inclusion of multicultural literature is not enough to disrupt privilege or injustice. Nor is it enough to ask teachers to deconstruct stereotypes in texts and images if teachers are unaware of the subtle biases that exist therein.

Conceptual Framework: Critical Literacy

The conceptual framework for this project is based on the pedagogies and theories in critical multicultural education and critical literacy (Freire, 1973). Critical multiculturalism dictates that teachers recognize the cultural, social and political factors in institutionalized racism and examine the school practices that contribute to the persistence of racism in schools and society. Importantly, children's literature can be a vehicle to examine social inequality (Chafel, Flint, Hammel, \& Pomeroy, 2007; Quintero, 2005; Vasquez, 2004). Our research focuses on Chicana/o children's literature, defined by Furumoto (in press) as "pre-K through adult literature written in English or in Spanish by U.S. based authors raised within local and immigrant Chicano/Latino cultures" (p.1). She emphasizes that Chicana/o children's literature is "born of struggle... [and] the themes, values and storylines reflected in Chicana/o children's literature connect to the lives of poor and working class families and create opportunities for dialogue and social justice activism" (p. 2). Thus, it is a logical to conclude that children's literature can be used to analyze past and present sociopolitical realities. However, many teachers are not trained in doing so.

When we ask preservice teachers to select a Chicana/o children's literature book, we find that some select literature simply because the color of the main character is a particular shade of brown or because the name of the character is "Maria" and not Mary. In other cases books are selected because they are written in two languages and/or are written by someone students believe is a Chicana/o author. Importantly, not all Chicano children's literature is authentic or reflects the complex reality of the Chicana/o experience. If literature is not grounded in the sociocultural and linguistic worlds of the Chicana/o child or if it does not represent Chicano/social realities in authentic or meaningful manner, then the deficit views that many of our students breathe in will persist unchallenged.

Chicano children's literature can be used to humanize the curriculum by presenting stories and situations of a group of people excluded from the "traditional" or mainstream curriculum. It can also be a springboard for teachers to critically analyze the policies that (mis)inform practice. However, not many individuals are trained to identify the ways in which children's literature can stereotype Chicana/o children, reject their linguistic realities, and/or minimize existing inequities. We recognize that it is particularly challenging for students to critically analyze a text when they are not conscious of what is "missing." It is our intent is to move preservice teachers beyond a surface-level inclusion of "other" cultures or a simplistic affirmation of cultural identity. We agree with 
Journal of Praxis in Multicultural Education, Vol. 3, No. 1 [2008], Art. 6

Nieto \& Bode (2008) that critical thinking must support agency for social change.

\section{Engaging Preservice Teachers in Critical Literacy}

We teach a course called the Chicana/o Child, which is designed to introduce students to the Chicana/o experience and prepare teachers to teach this growing demographic. For many prospective teachers this is the only opportunity they have to learn about Chicana/os in a university setting. As Chicana teacher educators, we embrace our obligation to teach our students the historical and contemporary experiences of Chicana/os. This entails teaching students to value and perceive other races/ethnicities as equal and also think critically about their own social, cultural, and political realities. It is with this in mind that we embarked upon our journey to use Chicana/o children's literature as a tool to move toward a critical analysis of what it means to be Chicana/o in today's world. Specifically, we engage preservice teachers in a process where they: (1) Identify key stereotypes, misconceptions and deficit views of Chicana/os and Latina/os in the United States, (2) Examine the extent to which texts portray the complexity and diversity of the Latina/o-Chicana/o experience, and (3) Design a critical literacy lesson/poster with images and questions to deepen their students' understanding of inequality, oppression, and social action. Our assignments are consistent with Banks' (1999) social action approach in which students "pursue projects and activities that allow them to take personal, social and civic action related to the concepts, problems and issues they have studied" (p. 32).

We engage our students in a questioning process proposed by Ada and Campoy (2004) where students move from a descriptive stage, where individuals simply provide a description/explanation of a book, to a deeper analysis of a text. The second stage in the process is the personal interpretive stage where students relate information found in a book to their own feelings, realties or experiences. The next stage is the critical multicultural or anti-bias stage, which requires reflection on the themes of equality and justice. In essence, readers delve into a critical analysis of (implicit or explicit) issues that emerge in the text. Finally, in the creative transformative stage, individuals translate their reflections into concrete outcomes in order to create change.

\section{The Critical Analysis of Children's Literature Assignment}

To set the stage for the transformative process described above, we examine common misconceptions about Latinos/Chicanos during the first few weeks of our course. After the first few weeks of class we ask our students to select children's literature that focuses on Latinos/Chicanos. After they select a book 
students are given a handout with a list of questions and sub-questions to guide them through a deeper analysis of the book (see appendix). Our preservice teachers are often thrilled to find their books and become personally attached to them. However, they are soon challenged as they answer the eleven questions we devised to strengthen their ability to critically analyze Chicana/o literature. We developed each question and sub-question in order to facilitate increasing levels of critical analysis. We sought to scaffold and engage teachers in difficult discourse that can often lead to dissonance and resistance to thinking or talking about race (e.g., Marx, 2006). Marx (2006) notes that "facing the topic can be challenging, frustrating, and even frightening experience for many" (p. 21). However, the imagery and text in children's literature can portray complex subjects in a manner that is concise, comprehensible, and often more palatable to potentially resistant educators.

We ease our students into the analysis by having them identify information about the book's author. The first set of questions requires students to analyze the authenticity of their book. Students must evaluate the background knowledge and cultural lenses of the author. The second question then asks students to examine the illustrations. Given that students may not readily recognize stereotypes, they are asked sub-questions such as: a) Is the clothing modern or quaint, traditional, or exotic?, b) Are the portrayals of Chicanos/Latinos stereotypical or limited/restricted to certain roles?, and c) Do the images portray the diversity within Chicanos/Latinos (e.g., SES, generation, and race)? These initial questions prepare students to think critically and answer the third question. It requires that students provide an overall assessment of the extent to which their books essentialize the Chicano/Latino experience.

After students begin to critically examine the representation of Chicano/Latinos, they are then prepared to answer the fourth question regarding the depth and centrality of the Chicano/Latino literary, historical, or cultural perspective. Unfortunately, the term multicultural primes students to think about values and traditions as opposed to engaging in a more critical analysis of sociopolitical realities. Hence, we devised the next set of questions to encourage preservice teachers to think critically about race, power, and positionality. We want our teachers to understand that power is differentially distributed in society and that social institutions are organized to advantage the most powerful (Villegas \& Lucas, 2002). Hence, the fifth question asks students to examine the extent to which Chicanos/Latinos are portrayed as equal in status/power when compared to other races/ethnicities. More specifically, students are asked to examine whether Chicanos/Latinos are portrayed in roles where they are leaders, intelligent, and/or decision-makers. These sub-questions are critical given that many students' understanding of privilege and power are often emergent and they can easily revert to simplistic summary statements. 
The sixth and seventh questions are, in fact, the most difficult for our students to answer because they require reflection upon issues of White privilege, racial inequality, and racialization (Lewis, 2003). These questions push students to reflect on "how race shapes social experience and educational outcomes" (Lewis, 2003, p. 7). To assist students in this process we provide a quote that captures the dynamics of race: "Race is more than color and hair texture; it is history, conquest, assimilation, resistance, and continued transaction manifested symbolically in physical characteristics" (Harris, 1999, p. 153). Specifically, the sixth question, engages students think about why a book would/should include racially and ethnically diverse characters. Interestingly, many students realize that the story lines in their books change minimally if the characters were a different race/ethnicity. At this point, students are compelled to revisit and reinforce their understanding of what constitutes authentic Chicana/o children's literature. For example, if they responded previously (question \#4) that the book provided an in-depth treatment of Chicano/Latino values, this question helps them reassess their response.

After examining the social significance of race in the text, they are prepared to examine specific relationships between the characters in the book. The seventh question asks students to examine the relationships between races/ethnicities and the extent to which the relationships resemble a utopian/idealistic/simplistic view of race relations and inequality (as opposed to the complex reality of race relations \& power struggles). One of the subquestions asks students to examine the race/ethnic relations in light of the historical context of the story/book. This question is particularly important since many texts strive to depict "modern-day" realities. Thus, students must examine their book in light of the context of our current society. With this broader context in mind, students then proceed to the eighth question and analyze whether inequality and racial/ethnic conflict are resolved in simplistic ways. Again, our sub-questions are critical in helping students identify the types of simplistic messages embedded within their books. For example, a) Is the main character so exceptional that he/she does not resemble an individual's typical experience/reality?, and b) Is the message in the book/story that an individual's determination or hard work is ALL one needs to succeed? The purpose of the latter question is to challenge the myth of meritocracy and the reality that oppressed peoples can simply will themselves out of poverty and racism.

The final set of three questions return to the initial goals, presumably, of our preservice teachers who choose to incorporate multicultural texts in the classroom. After thinking critically about whether Chicanos/Latinos are portrayed and equal in status/power and whether solutions to inequality are oversimplified, students are prepared to evaluate the impact of children's literature on a child. While students' responses to the first few questions on this assignment often extol the "beauty" of culture, they soon develop a more 
objective view of the text and its impact on children within a broader sociopolitical context. Specifically, the ninth question asks students to evaluate the impact of the book on a Chicano/Latino child's self-worth and their sense of empowerment. We deliberately phrase our question so that students recognize the diversity within the Chicano/Latino population. We ask: "If you are/were Chicano/Latino (e.g., light or dark complexion, indigenous or European features, low or high income, not Spanish-dominant, urbanite, etc.), what would you learn about yourself \& your group's self-worth?"

The tenth question then asks students to analyze the inclusion of Spanish or Indigenous languages in the text. Again, many students initially select a text simply because it is written in two languages. Many novice teachers presume that mere translations are what help students learn how to read in another language. Hence, one of our sub-questions pushes students to analyze the process of learning a language. For example, students are asked to determine whether the meaning of a word in Spanish or an indigenous language can be gleaned from the context of the passage. In addition, another subquestion asks teachers to assess whether including words in another language automatically motivates a native English speaker to learn another language. Again, we push our students to analyze their book in light of current sociopolitical realities. Lastly, the final question asks preservice teachers to think about whether their book meets specific academic purposes (and is not merely a fun, "add-on" to the "regular" curriculum). Specifically, teachers are asked to assess the developmental appropriateness of the text. In other words, what skills does the book build upon and how does it help a child advance in that given skill/ability?

\section{Preservice Teachers' Analysis of Chicana/o Children's Literature}

Upon completion of this assignment students begin to think critically about whether one book can capture the experience of all Latinos, whether race/ethnic relations are oversimplified, and whether a book empowers Chicano/Latino children and reinforces academic goals. Although the majority of our students begin to analyze Chicana/o children's literature with a more critical eye, not all students are equally successful with this assignment. Realistically, preservice teachers' dominant schemas about the Chicano/Latino child may not change significantly by simply completing one assignment. Some students still evaluate a book as "good" or "bad" based on whether a book communicates a commonsense solution to overcome prejudice (e.g., get to know others, celebrate differences) or whether it contains blatant stereotypes. It is important to note that even Chicana/o students can revert to a simplistic evaluation of Chicana/o 
children's literature. When students have minimal exposure to Chicano/a children's literature, they often become ecstatic about simply being able to find a book that contains Chicano/Latino characters or is written in two languages. Given that they can relate to the text on some level, they feel that they can counter any stereotypes that may exist in the text.

Unfortunately, preservice teachers are not necessarily taught the skills to analyze multicultural texts from a critical literacy framework. Students' limited capacity to examine inequality and children's literature (as political) is reflected in the following questions: "How do I know if U.S. values are seen as better [than Chicano/Latino values] if the story only talks about one family?," and "This book is not about race relations or inequality, so how can I answer some of these questions." In essence, students often need further scaffolding in order to develop the ability to examine the Chicano/Latino experience within a broader sociopolitical context. The schemas that are the most difficult to modify are preservice teachers' schemas about what impedes equality. For example, the perception that (1) a lack of knowledge about other cultures and/or (2) a lack of motivation to become more involved in school, reflects a simplistic analysis of racism and reinforces a deficit view of Chicanos/Latinos.

\section{The Critical Literacy Poster: A Deeper Analysis of Inequality \& Social Action}

To deepen preservice teachers' analysis of inequality in Chicana/o children's literature, we ask them to partner with someone, use the feedback from the children's literature assignment, and develop a critical literacy poster/lesson plan. Students are asked to choose one book for their critical literacy poster assignment and develop an objective related to inequality- derived from images or excerpts in the book. For example, if their book focuses on one family that lives in a Latino community, students can concentrate on the prevalence of residential segregation. If their book has an image that chastises a child for speaking Spanish, students can examine linguistic discrimination. The goal of the poster is to guide youth in a dialogue, analyze bias, and ultimately engage in social action. In the process of creating the lesson, preservice teachers must continue to analyze biases and inequality. Importantly, they also begin to develop ideas for social action.

Based on the critical literacy process described previously (Ada \& Campoy, 2004), preservice teachers must develop a set of questions related to the objectives they phrase for their target age group. The poster must include images from the text (to analyze) and a sample assessment activity (e.g., an acrostic) that conveys a child's understanding of the lesson objective(s). The critical literacy poster assignment requires our preservice teachers to (1) provide 
a short summary of the key concepts, ideas or themes within the book, (2) pose questions that facilitate an in-depth analysis of inequality, and (3) develop examples that move their students to social action. As mentioned previously, not all preservice teachers have an in-depth understanding of inequality at this point in the course. Thus, we do not ask our students to conduct lessons with youth, which may oversimplify inequality and/or race relations. Nevertheless, we believe that the critical literacy poster can be beneficial to youth in many ways.

The purpose of the critical literacy poster is to examine the multiple meanings of a text and bring to conscious awareness the subtext and implicit messages in a book. Analyzing how inequality is communicated or perpetuated in multicultural children's literature engages youth (and their teachers) in higherorder thinking. The series of questions that are posed engage youth in critical dialogue. In the process, youth will discover the different experiences and opinions within their classroom related to race/ethnic relations. Discussions about power dynamics are especially important for youth who are marginalized within the classroom and/or within the broader society. When a discussion is empowering, personally meaningful, and/or culturally relevant, a students' sense of competence may increase (e.g., Tan, 2001). This may serve to stimulate higher levels of participation between English language learners (ELLs) and non-ELLs alike given that youth are engaged in an activity where they can develop vocabulary in a meaningful context (as opposed to formulaic language devoid of context). Moreover, the images on the poster are akin to picture walks (prior to reading a text) and other learning strategies (e.g., activation of prior knowledge) that increase comprehension (Dougherty Stahl, 2004). Thus, through the critical literacy poster youth can develop an emerging sense of social consciousness and strengthen the power of their collective voice to contest inequities. Importantly, a growing sense empowerment is intertwined with the development of literacy and critical thinking skills.

The last phase of the critical literacy poster assignment involves preservice teachers writing a paper where they (1) Describe how a second book can deepen youth's understanding of inequality and how to address unequal power relations or (2) Develop an alternative ending to their book by deconstructing three biases (in status/power/outcomes). Students who choose the second prompt must also describe how the alternative ending deepens youth's understanding inequality and how to address unequal power relations. To ensure that our preservice teachers do not revert to empty phraseology, they are told that they will lose points on the assignment if they use words or phrases like respect, appreciation, awareness, tolerance, sensitivity, open-minded, special, unique, proud, celebrate differences, beauty of a culture, hero, and role model. This directive is quite effective at pushing students' thinking beyond a superficial analysis of inequality. The written description of the assignment also 
states clearly that their papers will be evaluated on whether they (a) Move beyond moral imperatives (e.g., "You should know better...it's wrong to..."), (b) move beyond simplistic solutions (e.g., Just work hard, "I made it... you can to" or "make friends with others" and (c) move beyond sympathy for others to actually stimulating change. Lastly, we remind students that equity refers to equality of outcomes (e.g., graduation rates) as opposed to equality of opportunities.

\section{The Students' Journey}

Upon analyzing our students' work we find that, at minimum, the simplistic conceptualizations of inequality are challenged. Their hidden biases are exposed and/or they struggle with finding new ways to have conversations about inequality without using phrases (e.g., teach everyone the beauty of a culture) they used to use to discuss inequality- phrases that do not communicate an understanding of the underlying structures that that perpetuate inequality. By the end of our course, our preservice teachers' (short) journey analyzing the Chicana/o experience can be captured by the following four patterns.

For some students, their journey in critical literacy stopped (not ended) at a basic understanding of hidden biases. They completed the assignments, but it was evident that an in-depth analysis of broader societal or environmental conditions did not take place. They may revert to an individual level analysis of racism and/or do not grasp the intensity of societal prejudices and

discrimination. For example, a student who read Abuela's Weave by Omar Castañeda (1993) "blamed" the grandmother for being so ashamed of the birthmark on her face that she left her granddaughter unsupervised. This student failed to recall the broader context of that situation in the text. (In the book, children had begun a rumor that she was a witch and as a result individuals were afraid of buying things from her. Thus, the grandmother told her granddaughter that she would walk a few steps behind her in order to maximize their selling potential. In the hustle and bustle of the market, however, she lost sight of her granddaughter.) In essence, some students "analyze" their books and conclude that individuals who experience prejudice do not try hard enough to overcome the prejudice or do enough to help their families. Interestingly, this deficit model of Chicanos/Latinos predominates even in the face of the richer context communicated within the pages of a children's book. Students with these type of responses are often (a) overworked students (of diverse races and ethnicities) with minimal time for deep reflection, (b) students who essentially ask for the basic parameters of the assignment and neglect to read the detailed subquestions, and (c) students who do not want to engage in deep reflection or meaningful engagement with the project. In essence, students may not have 
time, do not prioritize, or choose not to devote their time and energy to one or more of the projects in the course.

A second group of students' journey stops at an examination of one experience or historical incident in more depth, such as family ties or immigration. However, they revert to a surface-level analysis of inequality and do not describe their books in relation to the broader sociopolitical realities of the Chicana/o community. For example, after reading Pepita talks twice (Dumas Lachtman, 1995), a Latina student decided to encourage her students to speak their primary language in school. However, she did not examine the politics of bilingual education and language policies within her critical literacy poster. Again, it is important to note that even students who revert to a surfacelevel analysis can simultaneously come to the realization that a book is simplistic and lacks depth (e.g., a student described a book as "trite"). The students in this group often come to the course with the mindset that they can learn and get all of the answers to their questions about the Chicana/o child during the course of one semester. When they devise their assessment activities and social action activities, they revert to the idea that once a child learns English or once parents help children with their homework, then children will have guaranteed academic success. In other words, these students have not shed their deficit views. They focus on individual-level solutions and do not examine issues, like xenophobia or anti-immigrant sentiment, in their critical literacy posters.

Further along in the continuum of understanding sociopolitical realities are students whose hidden biases are exposed, who can analyze broader issues of inequality, and who attempt to reconcile their insights with their previous views. For example, one student conducted an insightful analysis of a book she initially thought was a "great" story (i.e., Cheech the School Bus Driver by Cheech Marin (2007)) about a mariachi band that won a contest. This student's superb analytic skills were evident when she wrote, "Do you think the mariachi group would have been better liked by the crowd if they performed with their weird costumes and louder music like the group in the picture." This question, posed in her critical literacy poster, lends itself to a conversation about whether out-group members are more easily accepted if they present themselves in humorous (non-threatening) ways. She also asked, "Would the rock and roll group [who are pictured laughing at the mariachi group] have reacted differently to a group performing country or hip hop music?" Thus, this student's questions engage youth to think about who is perceived in society as having equal power, status, and worth. Students who fall into this category include (a) White students who have had experience resolving a specific "issue" in their classroom or school related to Chicanos/Latinos, and (b) Chicano/Latino students whose ability to analyze sociopolitical issues had been previously untapped within a university setting. The Chicana/o students in this category often feel validated 
for the first time in their academic careers because they discover that they have a skill that is not typically valued by academia. One Chicana student, for example, approached her professor and confessed that never in her life had her Chicana/o culture been the focal point of a course. She felt "so [extremely] proud" working with her non-Chicana partner. The prospective teachers in this category often tell stories or bring articles to class to share with their professors that reflect their experiences with Chicano/Latino youth and families.

Lastly, students who enter the class with an incipient or developing activism leave our class and continue their journey with an invigorated or reinvigorated activism. For instance, one student, who selected the book $L a$ Llaman America (Rodriguez, 1997), was empowered to share her bilingualism, biculturalism, and impassioned views on anti-immigrant sentiment. She openly and continually shared her knowledge about cultural events, political demonstrations and issues impacting the Chicano/Latino community. After reading La Llaman America (Rodriguez, 1997), activist students generated ideas to encourage students to advocate on behalf of undocumented youth.

\section{Conclusion}

As teacher educators, in a Chicana/o Studies department at a large urban comprehensive university, it is our responsibility to prepare our university students to teach in state where over $44 \%$ of the student body is Latino and where the surrounding school districts are 60-80\% Latino. We, and others (Ada \& Campoy, 2004), recognize the benefits of using multicultural children's literature as a tool to foster literacy and academic development. When teachers incorporate multicultural texts they not only foster critical consciousness, but also simultaneously foster literacy development and further empower youth. In designing this project, we aspired to have students move beyond a surface-level or stereotypical view of Chicanos/Latinos toward a critical analysis of the sociopolitical context and how it impacts the historical and contemporary experiences of the Chicana/o community. Ultimately, teachers can become stronger advocates for youth and develop their voices so that they can exert their collective power.

As Edelsky \& Cherland (2006), argue the goal of critical literacy is to question and transform inequitable institutions. Hence, it is not our intent to present Chicano children's literature to "celebrate diversity" and merely expose our preservice teachers to "colorful" characters that speak Spanish. We devised our assignments to (1) scaffold preservice teachers' examination of hidden biases and simplistic messages about race, (2) engage them (and their students) in a dialogue fosters an analysis of inequality, and (3) move them to social action. We understand that students can easily revert to simplistic views about race and 
how to address inequality (e.g., White \& Parham, 1990). Thus, we carefully developed sub-questions in the critical literacy assignment and told students to avoid certain phrases in their posters in order to engage them in a deeper analysis of inequality.

At minimum, our assignments led preservice teachers to engage in a critical analysis of Chicana/o children's literature, which challenged simplistic conceptualizations of race/ethnicity and inequality. Our preservice teachers' journey paralleled theories of racial identity development in which individuals move from a raceless identity to one in which they take social action (e.g., Cross, 1991; Helms, 1990). But as noted earlier, individuals are prone to reverting to prior conceptualizations about race and inequality (e.g., White \& Parham, 1990). On one end of the continuum, a few students may refuse to see issues of inequity and simply not want to talk about "it." For example, in the final paper that prompted students to develop an alternate ending, one White student simply changed the pictures in the book into a multicultural setting. She interpreted the book as "segregationist," colored the pictures, and converted the setting into an international, festive scene. Despite having analyzed Chicana/o children's literature, this student reverted to her dominant schema of race as something that should not be discussed. This is consistent with Escamilla \& Nathenson-Mejia (2003) who found that that preservice teachers shy away from controversial subjects in children's literature (e.g., attention to dark skin, breaking the law). In other words, preservice teachers are often more comfortable with multicultural stories about interpersonal acceptance rather than those that examine social/structural dimensions of racism. In addition, they are less likely to endorse discussions about White privilege given their perception that it will be divisive (e.g., Montecinos \& Rios, 1999). In fact, a teacher in a study by Montecinos \& Rios (1999) supported his/her position by stating that riots during the 1960s provided evidence that a social reconstructionist approach was not effective.

Importantly, Chicana/o children's literature can engage teachers and students in personal reflection, raise student consciousness, and facilitate discourse about the systematic inequality inherent in our schools that impedes education success. Our hope is that our preservice teachers' critical literacy posters can serve as a vehicle to engage more preservice teachers to engage their students in the process of transforming the world. Teachers who use critical literacy to analyze Chicana/o children's literature will stimulate discussions about what it is like to contend with the realities of anti-immigrant sentiment, attacks on bilingualism and social inequality. In addition, a culturally responsive teacher would understand the politics of learning a language cannot be dissociated from the stereotypes and (stigmas) of a racial/ethnic group.

The presentation of complex political and social issues is not merely an exercise in critical thinking, but must be accompanied by an opportunity for 
students to experience the benefits of social action (e.g., Montecinos \& Rios, 1999). This is consistent with our finding that the teachers who moved further along in their journey of analyzing the sociopolitical context of Chicanos/Latinos already had meaningful relationships with Chicanos/Latinos. For example, the White teachers who sought to reconcile their insights with their previous views played a key role on "solving" an issue with Chicanos/Latinos in their classrooms. As Landerman, Rasmussen, King, \& Jiang (2007) found, the development of critical conscious is not linear. It requires sustained involvement in reflection, ongoing engagement in social action, and supportive social networks that facilitate the development of critical consciousness (Landerman et. al, 2007).

In essence, we hope that future educators not only reflect upon the positional reality Chicana/os encounter, but also engage in critical dialogue with others about injustice and ultimately take action to eliminate the inequality and injustice. However, we do not purport that our projects will move all preservice teacher to political or social action. In fact, the students who implemented plans for social action in our course already had an emerging activist identity. Nevertheless all of our prospective teachers were exposed to the important role that social action plays in changing unjust situations. The promotion of equity in education necessitates going beyond incorporating other cultures or providing more resources to poor schools. We devised our assignments to push our students to think of ways to "work for equality and fairness both in and out of school" (Nieto \& Bode, 2008, p. 12). Without fundamentally changing the inequitable structure of schooling, such practices will not result in equality.

\section{References}

Ada, A.F. \& Campoy, F.I. (2004). Authors in the classroom: A transformative education process. New York, NY: Pearson/Allyn \& Bacon.

August, D., \& Shanahan, T. (2006). Developing literacy in second-language learners: Report of the National Literacy Panel on Language-Minority Children and Youth. Mahwah, NJ. Lawrence Erlbaum.

Baker, C. (2001). Foundations of bilingual education and bilingualism. Tonawanda, NY: Multilingual Matters Ltd.

Banks, J. (1999). An introduction to multicultural education. New York, NY: Allyn \& Bacon.

Brookhart, S.M., \& Freeman, D.J. (1992). Characteristics of entering teacher candidates. Review of Educational Research, 62(1), 37-60.

Castañeda, O. (1993). Abuela's weave. New York, NY: Lee and Low.

Collier, V.P. \& Thomas, W.P. (1988). Acquisition of cognitive-academic second language proficiency: A six-year study. Paper presented at the meeting of the American Educational Research Association, New Orleans, LA. 
Chafel, J.A., Flint A.S., Hammel, J., \& Pomeroy, K.H. (2007). Young children, social issues, and critical literacy: Stories of teachers and researchers. Young Children, 62(1), 73-81.

Crawford, J. (2007). Leaving most vulnerable students behind. NYSUT News wire. Retrieved January 26, 2008, from http://nysut.org

Cross, W.E. (1991). Shades of Black: Diversity in African-American identity. Philadelphia, PA: Temple University Press.

Cummins, J. (1994). Primary language instruction and the education of language minority students. In C.F. Leyba (Ed.), Schooling and language minority students: A theoretical framework (pp. 3-46). Los Angeles, CA: Evaluation, Dissemination and Assessment Center, California State University.

Cummins, J. (1981). The role of primary language development in promoting educational success for language minority students. In C.F. Leyba (Ed.), Schooling and language minority students: A theoretical framework (pp. 3-49). Los Angeles, CA: Evaluation, Dissemination and Assessment Center, California State University.

Dougherty Stahl, K.A. (2004). Proof, practice, and promise: Comprehension strategy instruction in the primary grades. The Reading Teacher, 57, 598-609.

Dumas Lachtman, O. (1995). Pepita talks twice. Houston, TX: Piñata Books.

Easter, L.M., Shultz, E.L., Neyhart, T.K, \& Reck, U.M. (1999). Weight perceptions: A study of the attitudes and beliefs of pre-service teacher education students regarding diversity and urban education. The Urban Review, 31(2), 205-220.

Edelsky, C., \& Cherland, M. (2006). A critical issue in critical literacy: The 'popularity effect.' In K. Cooper \& R.E. White (Eds.), The practical critical educator (pp. 17-33). The Netherlands, Springer.

Education Data Partnership (2007). Los Angeles county profile. Retrieved June 8, 2008, from http://www.ed-data.k12.ca.us

Escamilla, K. \& Nathenson-Mejia (2003). Preparing culturally responsive teachers: Using Latino children's literature in teacher education. Equity \& Excellence in Education, 36, 238-248.

Freire, P. (1973). Education for critical consciousness. New York, NY: Continuum.

Furumoto, R. (in press). Future teachers and families explore humanization through Chicana/o Latina/o children's literature. In V. Lea \& E.J. Sims (Ed.), Undoing Whiteness in the classroom: Different origins, shared commitment. New York, NY: Peter Lang.

Gutierrez, K. D., Asato, J., \& Pacheco, M., Moll, L.C., Olson, K., Horng, E.L., Ruiz, R., Garcia, E., \& McCarty, T.L. (2002). Sounding American: The consequences of new reforms on English language learners. Reading Research Quarterly, 37, 328-343.

Harris, V.J. (1999). Applying critical theories to children's literature. Theory into Practice, 38, 147-154.

Helms, J. (1990). Black and White racial identity: Theory, research, \& practice. Westport, CT: Greenwood.

Kibler, J.M (1996). Latino voices in children's literature: Instructional approaches for developing cultural understanding in the classroom. In J. LeBlanc Flores (Ed.), 
Journal of Praxis in Multicultural Education, Vol. 3, No. 1 [2008], Art. 6

Children of la frontera: Binational efforts to serve Mexican migrant and immigrant students (pp. 239-268). Charleston, WV: ERIC Clearinghouse.

Landerman, L.M., Rasmussen, C.J., King, P.M., \& Jiang, C.X. (2007). A phenomenological study of the development of university educators' critical consciousness, Journal of College Student Development, 48(3), 275-296.

Lewis, A.E. (2006). Race in the Schoolyard: Negotiating color line in classrooms and communities. Piscataway, NJ: Rutgers University Press.

Marin, C. (2007). Cheech the school bus driver. New York, NY: Harper Collins.

Marx, S. (2006). Revealing the invisible: Confronting passive racism in teacher education. New York, NY: Routledge Press.

Montaño, T. \& López-Metcalfe (2003). Triumphs and tragedies: The urban schooling of Latino students. In V.I. Kloosterman (Ed.), Latino students in American schools: Historical and contemporary views (pp. 139-152). Westport, CT: Praeger.

Montecinos, C, \& Rios, F. (1999). A heuristic device for assessing preservice teachers' sense of concern \& comfort with multicultural education. Teacher Education Quarterly, 26(3), 7-24.

Nieto, S. \& Bode, P. (2008). Affirming diversity: The sociopolitical context of multicultural education. Boston, MA: Allyn and Bacon.

Quintero, E. (2005). Multicultural literature: A source of meaningful content for kindergartners. Young Children, 60(6), 28-32.

Rodriguez, L. (1997) La llaman America. Willimantic, CT: Curbstone Press.

Shedivy, S. (2007). Lies my Spanish textbooks tell. Rethinking Schools, 21(3). Retrieved August 25, 2008, from http://www.rethinkingschools.org/archive/21_03/lies213.shtml

Smith, H.L., and Heckman, P.E. (1995). The Mexican-American war: The next generation. In E.E. Garcia \& B. McLaughlin (Eds.), Meeting the challenge of linguistic and cultural diversity in early childhood education (pp. 64-84). New York, NY: Teachers College Press.

Tan, G. (2001). "I want my teachers to like me": Multiculturalism and school dropout rates among Mexican Americans. Equity \& Excellence in Education, 34(2), 3542.

Ulanoff, S. H. \& Vega-Castaneda, L. (1999). The sins of the fathers: Examining teacher narratives on the implementation of Proposition 227. Paper presented at the $20^{\text {th }}$ Annual Ethnography in Education Research Forum, Philadelphia, PA.

Vasquez, V.M. (2004). Negotiating critical literacies with young children. Mahwah, NJ: Lawrence Erlbaum.

Villegas, A.M., \& Lucas, T. (2002). Preparing culturally responsive teachers: Rethinking the curriculum. Journal of Teacher Education, 53, 20-32.

White, J.L., \& Parham, T.A. (1990). The Psychology of Blacks: An African-American perspective (2nd ed.). Englewood-Cliffs, NJ: Prentice-Hall. 
Appendix

\section{Guiding Questions to Assess Effective Chicana/o Children's Literature}

I. Analysis of authenticity and diverse representation within Chicanos/Latinos

1) Author's background/research

- Does the author have an "insider" perspective?

- Does the author have an informed "outsider" perspective about the Chicano/Latino experience \&/or literary styles?

- Is the story about the author's life, research of a racial/ethnic group, or based on any background knowledge?

ASSESS: Based on the author's background/experience, to what extent is the story/book "authentic?"

2) Analysis of illustrations

- Are the characters raceless?

- Are there stereotypes conveyed in the images?

- Are there restricted portrayals of the settings of Chicanos/Latinos (e.g., ghetto, barrio; migrant)?

- Are the portrayals of Chicanos/Latinos limited/restricted to certain roles or images?

- Is the main character pictured Chicano/Latino?

- Is the clothing modern or quaint, traditional, or exotic?

- Do the images portray the diversity within Chicanos/Latinos (e.g., SES, generation, race)?

ASSESS: To what extent are the characters \& setting raceless or hyper-traditionalized or stereotypical (versus a portrayal of the diversity within Chicanos/Latinos)?

3) Diversity of the Chicano/Latino experience vs. essentialism 
Journal of Praxis in Multicultural Education, Vol. 3, No. 1 [2008], Art. 6

- Does the book/story reflect the diversity of the Chicano/Latino experience? (e.g., languages spoken, different generations, different races, refugee status)

- Are there restricted portrayals of the setting or images of Chicanos/Latinos (e.g., barrio, farm)?

ASSESS: To what extent does the book/story reflect the diversity of experience among Chicanos/Latinos?

4) Centrality of the Chicano/Latino literary, historical, or cultural perspective

- Does the book/story omit significant cultural or historical information?

- Is there genuine insight into the life of Chicano/Latino families or youth?

- Are key values, beliefs, perspectives of Chicano/Latino culture consistently integrated or interwoven throughout the story's plot?

ASSESS: To what extent is there an in-depth (vs. superficial) analysis of the complexity/dynamics of culture or race?

II. Critical analysis of power and positionality

5) Portrayal of Chicanos/Latinos in high status roles \& equal power

- Is the Central/main character in the story Chicano/Latino?

- Are Chicanos/Latinos in decision making roles or positions of high status/power?

- Are Chicanos/Latinos portrayed as intelligent/leaders?

- Are Chicano/Latino values portrayed as the same or similar to U.S. values?

- Are Chicano/Latino values portrayed as unique, but positive?

- Are Chicano/Latino values portrayed as inferior/negative compared to U.S. values?

ASSESS: To what extent are Chicanos/Latinos portrayed as equal in status/power compared to other races/ethnicities?

6) Centrality \& significance of race and inequality 
Think about it: "Race is more than color and hair texture; it is history, conquest, assimilation, resistance, and continued transaction manifested symbolically in physical characteristics" (Harris, p. 153, 1999)

- Is race or inequality (of power/status) a central theme in the book?

- Does the inclusion of race appear like a gesture to include "diversity," but in actuality race and inequality are not significant threads in the book/story?

- Would the story change significantly if the characters were not Chicano/Latino? (see Harris, 1999)

- Does the book perpetuate stereotypes or deconstruct them?

ASSESS: What is the purpose or significance of the racialized characters in the book/story?

\section{7) Inequality \& race relations between the characters}

- Given the historical context of the story/book, are Whites \& Latinos portrayed as equal in status?

- Are relationships portrayed in depth or are they portrayed superficially or idealistically?

- "Does it [the book address or] develop constructive attitudes toward [potential] conflict, ambiguity, \& change?" (Kibler, 1997, p. 257)

ASSESS: To what extent do the relationships between the races/ethnicities resemble a utopia/idealistic/simplistic view of race relations \& inequality (vs. the complex reality of race relations \& power struggles)?

8) Resolution of inequality \& racial/ethnic conflict

- Is the idea of loving each other the primary way the book/story resolves inequality or "misunderstandings" across races?

- Is the message in the book/story that children just need to have good self-esteem to defy/overcome stereotypes?

- Is the message in the book/story that an individual's determination or hard work is ALL one needs to succeed (or does it examine the multiple factors contributing to poverty)?

- Is the main character so exceptional (e.g., a token minority) that he/she does not resemble an individual's typical experience/reality? 
Journal of Praxis in Multicultural Education, Vol. 3, No. 1 [2008], Art. 6

- Do we develop sympathy for characters or are we moved to action or advocacy to address injustices?

ASSESS: To what extent are resolutions to inequality or racial conflict simplistic (vs. reflect complex sociopolitical realities)? 
III. Analysis of children's sense of empowerment and academic competence

9) Effects on Chicano/Latino child's self-image

- Are Chicanos/Latinos portrayed as intelligent/leaders/exemplars?

- Are Chicanos/Latinos portrayed in "professional" roles?

- Is the depth and equal value of "non-professional" occupations communicated?

- What standards of beauty are communicated?

- Are Chicanos/Latinos portrayed as interesting, quaint, exotic, or strange?

- Is pride or self-worth primarily derived from images of Chicanos/Latinos as being "cool" or having good food or "fun" celebrations?

- Is the portrayal of a historical figure disconnected from a child's current reality/experience?

- Would Chicanos/Latinos feel empowered or have heightened feelings of self-determination after reading the book/story?

ASSESS: If you are/were Chicano/Latino (e.g., light or dark complexion, indigenous or European features, low or high income, not Spanish-dominant, urbanite, etc.), what would you learn about yourself \& your group's self-worth?

10) Inclusion of the Spanish language

- Are words in Spanish integrated throughout the text in such a way that a child could try to glean the meaning of the word as it is used in the context of the passage?

- Is the Spanish translation of each paragraph underneath or on the right of the English text?

- Are Spanish phrases integrated in the text and is a glossary of the words provided? 
- Realistically, will a non-Spanish speaking child take the time to understand the words or phrases or paragraphs in Spanish?

ASSESS: To what extent does the use of Spanish invite or engage Spanish and non-Spanish speakers to learn/read or want to learn/read another language?

11) Developmental appropriateness of the book/story

- What is the target age group for this book?

- How is this book/story uniquely appropriate for children in that age group?

- Does the book build on skills that youth at that age are learning (e.g., metaphors, punctuation in a dialogue, phonemic awareness, cause \& effect)?

- Does the book challenge the existing skills or "ability" levels for that age group?

- Is the book easy for children of that age to relate to or understand the book/story?

ASSESS: To what extent is the book developmentally appropriate \& engaging for the target age group? 